\title{
Developing New Type of High Temperature Alloys - High Entropy Superalloys
}

A.C Yeh $^{1^{*}}$, T. K. Tsao ${ }^{1}$, Y.J.Chang ${ }^{1}$, K.C. Chang ${ }^{1}$, J.W. Yeh ${ }^{1}$, M.S. Chiou ${ }^{2}$, S.R. Jian ${ }^{2}$, C.M. Kuo ${ }^{3}$, W.R. Wang ${ }^{4}$, H. Murakami ${ }^{5}$

${ }^{1}$ Department of Materials Science and Engineering, National Tsing Hua University, Hsinchu, 30013, Taiwan R.O.C.

${ }^{2}$ Department of Materials Science and Engineering, I-Shou University, Kaohsiung, 84001, Taiwan R.O.C.

${ }^{3}$ Department of Mechanical and Automation Engineering, I-Shou University, Kaohsiung, 84001, Taiwan R.O.C.

${ }^{4}$ Clean Energy and Eco-technology Center, Industrial Technology Research Institute, Tainan, 70955, Taiwan R.O.C.

${ }^{5}$ National Institute for Materials Science, Sengen 1-2-1, Tsukuba, Ibaraki, 305-0047, Japan

Abstract
Novel high temperature alloys - high entropy superalloys (HESA) have been developed by elevating
the mixing entropies of Ni-Al-Co-Cr-Fe-Ti systems, these alloys contain stable FCC $\gamma$ matrix and $\mathrm{L}_{2} \gamma^{\prime}$
precipitates; compositions spaces are outside the scopes of traditional Ni-base superalloys and equimolar
high entropy alloys. The thermal stability of high entropy $\gamma^{\prime}$ precipitates can be enhanced through alloy
design by thermodynamic calculation based on Thermo-Calc. HESAs have potentials to high temperature
structural application; alloy densities are below $8.0 \mathrm{~g} / \mathrm{cm}^{3}$ with lower cost of raw materials than those of
conventional Ni-base superalloys.

Publication History:

Received: March 25, 2015

Accepted: June 23, 2015

Published: June 25, 2015

\section{Keywords:}

High entropy alloys, Superalloys, High temperature strength, Phase stability

\section{Introduction}

Aerospace, energy, and oil \& gas sectors have relied on Ni-based superalloys-made components in order to operate gas turbine engines $[1,2]$. These superalloys have relied on dispersion of coherent $\mathrm{L}_{2} \gamma^{\prime}$ precipitates in FCC $\gamma$ matrix for excellent high temperature mechanical properties. Compositions of superalloys have continued to evolve to meet demanding operation conditions [3]. Recently, additions of Re and $\mathrm{Ru}$ in superalloys have led to much improvement in creep strength [4-12], however, $\mathrm{Re}$ and $\mathrm{Ru}$ additions can render alloys to possess higher density and higher cost. Furthermore, the compositions of cast superalloys have to exhibit good castability, however addition of heavy elements $(\mathrm{Re}, \mathrm{W})$ tends to cause density inversion and results the formation of casting freckle defects [13]. Traditional alloy design methods that rely on addition of refractory elements have appeared to reach the limit. High entropy alloys (HEAs) are defined to have at least five principal elements with the concentration of each principal element being between 35 and 5 at\% [14]. There are four core effects associated with HEAs, i.e. (1) high-entropy, (2) sluggish-diffusion, (3) lattice-distortion and (4) cocktail effects [15]. In this paper, a new type of high temperature alloy has been derived from the concept of high entropy alloy and allows the four core effects to be exploited for high temperature applications. These novel alloy systems (density $<8.0 \mathrm{~g} /$ $\mathrm{cm}^{3}$ ) based on non-equimolar Al-Co-Cr-Fe-Ni-Ti systems containing FCC $\gamma$ matrix with uniform dispersion of $\mathrm{L}_{2} \gamma^{\prime}$ particles have been developed. Since alloy compositions are designed by the high entropy alloy concept, and their microstructures can resemble that of conventional superalloys, hence the term "High Entropy Superalloys (HESA)" has been given.

In our previous work, $\mathrm{Co}_{1.5} \mathrm{CrFeNi}_{1.5} \mathrm{Ti}_{0.5}$ high entropy alloy contain $\gamma^{\prime}+\gamma+\eta$ phases in its microstructure [16]; this alloy could be fabricated into single crystal by the conventional Bridgeman method, and its single crystal castability is similar to that of conventional Ni-base superalloys. However, $\eta$ phase is a detrimental phase, and Thermo-Calc (TCNI5 database) has been utilized to perform alloy design to ensure that microstructure can contain mostly $\gamma$ and $\gamma^{\prime}$, Figure 1. Interestingly, this path of alloy design has leaded us into composition spaces that have not really been exploited before. Compositions spaces are actually outside the scopes of traditional Nibase superalloys and equimolar high entropy alloys, Figure 2 .
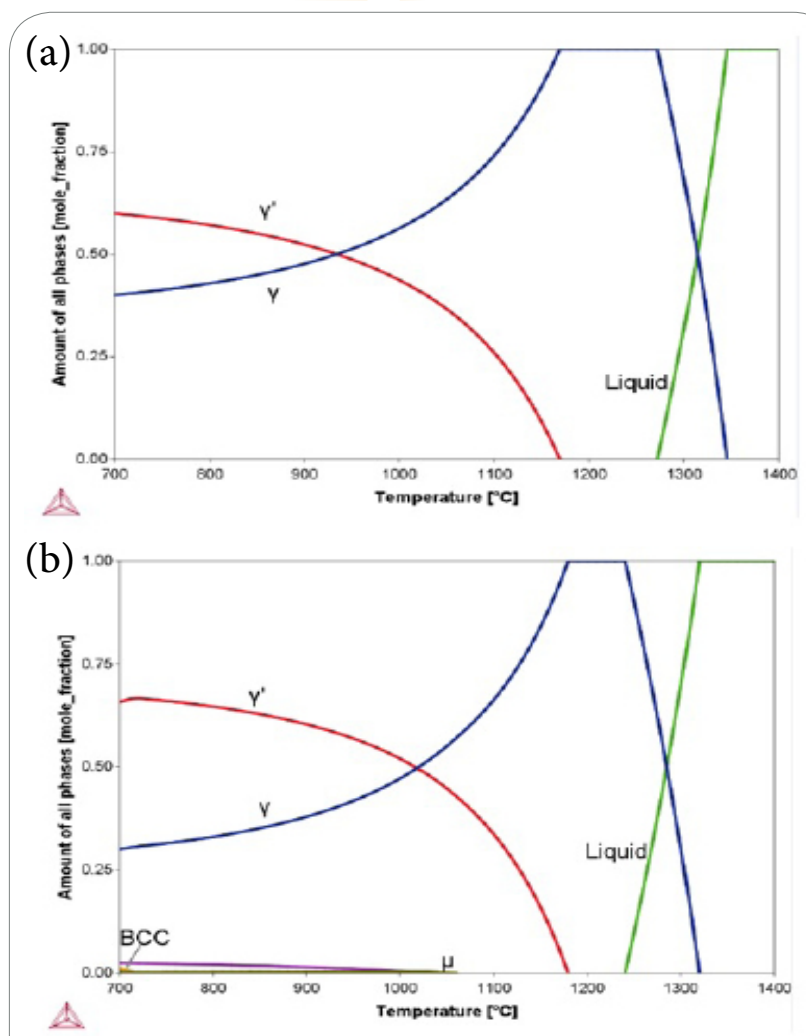

Figure 1: Designing alloy compositions by CALPHAD-base simulations (Thermo-Calc: TCNI5 database) (a) Alloy A, and (b) Alloy C.

"Corresponding Author: Prof. An-Chou Yeh, Department of Materials Science and Engineering, National Tsing Hua University, Hsinchu, 30013, Taiwan R.O.C.; E-mail: yehac@mx.nthu.edu.tw

Citation: Yeh AC, Tsao TK, Chang YJ, Chang KC, Yeh JW, et al. (2015) Developing New Type of High Temperature Alloys-High Entropy Superalloys. Int J Metall Mater Eng 1: 107. doi: http://dx.doi.org/10.15344/2455-2372/2015/107

Copyright: @ 2015 Yeh et al. This is an open-access article distributed under the terms of the Creative Commons Attribution License, which permits unrestricted use, distribution, and reproduction in any medium, provided the original author and source are credited. 
Citation: Yeh AC, Tsao TK, Chang YJ, Chang KC, Yeh JW, et al. (2015) Developing New Type of High Temperature Alloys-High Entropy Superalloys. Int J Metall Mater Eng 1: 107. doi: http://dx.doi.org/10.15344/2455-2372/2015/107

Page 2 of 4

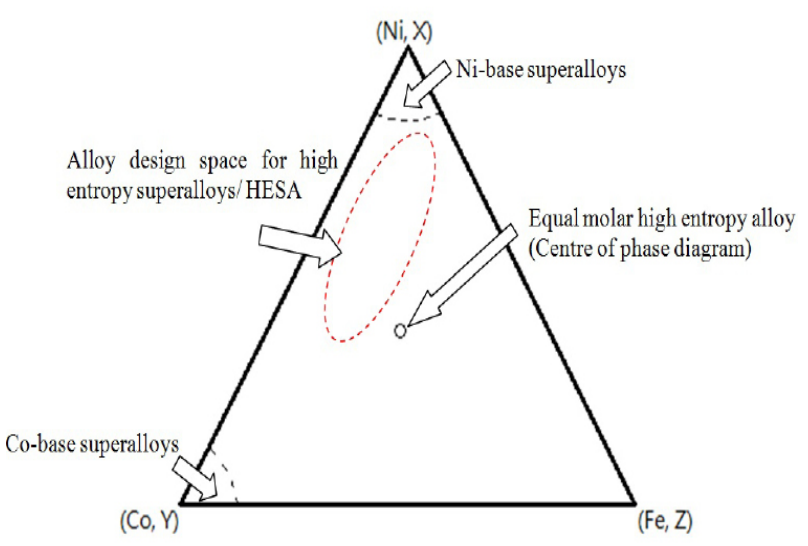

Figure 2: Illustration of the alloy design space for high entropy superalloys.

Table 1 lists three example compositions of HESA; the mixing entropy is calculated by the following equation: $\Delta S_{\text {mix }}=-R\left(X_{A} \ln X_{A}+\right.$ $\left.X_{B} \ln X_{B}+\cdots\right)$, where $\Delta \mathrm{S}_{\text {mix }}$ is the mixing entropy of alloy, $\mathrm{R}$ is the gas constant, and $X_{A}$ means the molar fraction of constituent $\mathrm{A}$ in whole alloy, $X_{B}$ means the molar fraction of constituent $\mathrm{B}$, and so on. Unlike conventional Ni-base superalloys, their densities are below $8.0 \mathrm{~g} / \mathrm{cm}^{3}$ and raw materials cost can be $20 \%$ less than that of $1^{\text {st }}$ generation superalloys, such as CM247LC.
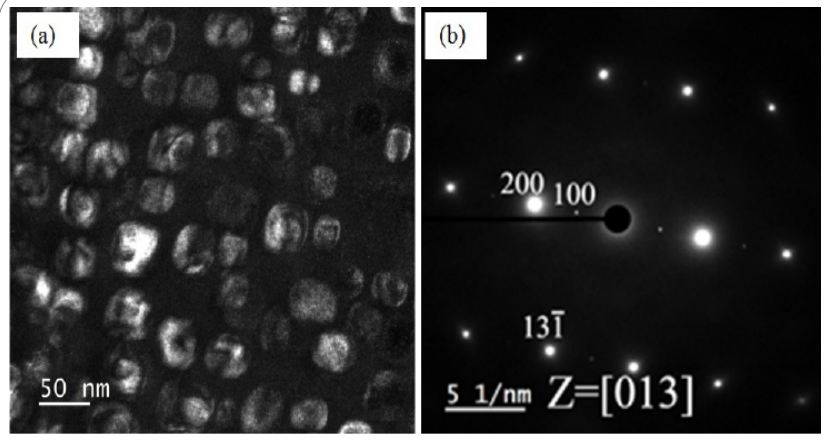

Figure 4: TEM analysis on HESA sample (a) Dark field image shows $\gamma^{\prime}$ particles in $\gamma$ matrix, (b) Diffraction patterns shows the superlattice reflection of $\gamma^{\prime}$.

The high temperature phase stability of HESA is excellent. The $\gamma$ solvus temperatures of Alloy $\mathrm{A}, \mathrm{B}$ and $\mathrm{C}$ are measured by differential thermal analysis to be $1,146^{\circ} \mathrm{C}, 1,165^{\circ} \mathrm{C}$, and $1,194^{\circ} \mathrm{C}$, respectively. After isothermal ageing at $1,050^{\circ} \mathrm{C}$ for $500 \mathrm{hrs}$, microstructures of HESA remain stable $\gamma-\gamma^{\prime}$ with no $\mu, \sigma, \eta, \delta, \beta$ detrimental phase formations, Figure 5. Conventional Ni-Fe base superalloys can only contain $\mathrm{Ni}_{3}(\mathrm{Al}, \mathrm{Ti}) \gamma^{\prime}$ within a fairly narrow range of $\mathrm{Al} / \mathrm{Ti}$ ratios [1]. As the $\mathrm{Al}$ content is increased for a given Ti level in these alloys, the sequence of stable phases includes hexagonal $\mathrm{Ni}_{3} \mathrm{Ti}(\eta), \mathrm{Ni}_{3}(\mathrm{Ti}, \mathrm{Al})$ $\left(\gamma^{\prime}\right)$, cubic $\mathrm{Ni}_{2} \mathrm{AlTi}$ (Heussler phase), cubic $\mathrm{Ni}(\mathrm{Al}, \mathrm{Ti})(\beta)$. And, among

\begin{tabular}{|l|l|l|l|l|l|l|l|l|l|l|l|}
\hline Alloys & Ni & Al & Co & Cr & Fe & Ti & Ta & Mo & W & $\Delta S_{\text {mix }}$ & $\begin{array}{l}\text { density } \\
(\mathrm{g} / \mathrm{cm} 3)\end{array}$ \\
\hline A & 50.5 & 8.9 & 17.2 & 9.2 & 8.2 & 6.0 & -- & -- & -- & $-1.46 \mathrm{R}$ & 7.68 \\
\hline B & 40.7 & 7.8 & 20.6 & 12.2 & 11.5 & 7.2 & -- & -- & -- & $-1.58 \mathrm{R}$ & 7.64 \\
\hline C & 48.6 & 10.3 & 17.0 & 7.5 & 9.0 & 5.8 & 0.6 & 0.8 & 0.4 & $-1.56 \mathrm{R}$ & 7.94 \\
\hline
\end{tabular}

Table 1: The nominal composition, mixing entropy and $\gamma^{\prime}$ solvus of some HESA systems (at\%).

The sample preparation procedure involved making master alloys by the arc-melting process, the mixtures of the constituent elements were with purities higher than $99.5 \mathrm{wt} \%$ in an argon atmosphere, and the melting processes were repeated four times to ensure chemical homogeneity of the master alloy. The next process was directional solidification casting, by referring to our previous work [16], 120 $\mathrm{mm}$ in height and $9 \mathrm{~mm}$ in diameter directional solidified (DS) bars were fabricated by the conventional Bridgeman furnace with DS seed material of Rene 142 obtained from in-house casting. The withdrawing of the single crystal cast started after the mold temperature was stable at $1,550^{\circ} \mathrm{C}$ with a withdraw rate of $40 \mathrm{~mm} / \mathrm{hour}$, and a temperature gradient $\sim 30^{\circ} \mathrm{C} / \mathrm{mm}$. The as-cast microstructure contains dendritic structure; phase constituents include only FCC $\gamma$ matrix and coherent $\mathrm{L}_{2} \gamma^{\prime}$ phases, Figure 3. The existence of ordered $\mathrm{L}_{2} \gamma^{\prime}$ phases was proven by the superlattice diffractions in Figure 4.
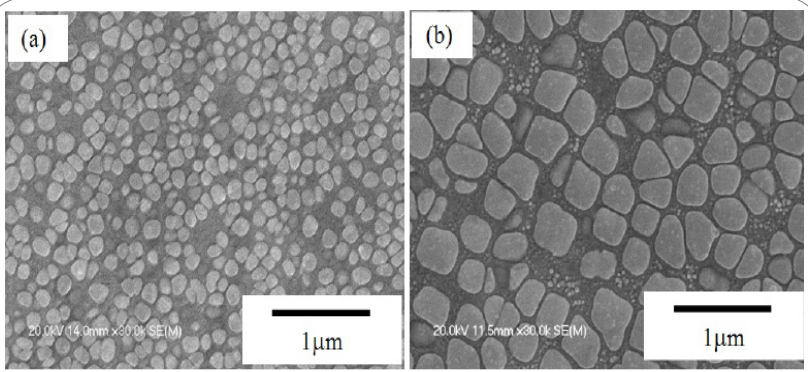

Figure 3: SEM micrographs of as-cast (a) Alloy B, and (b) Alloy C.
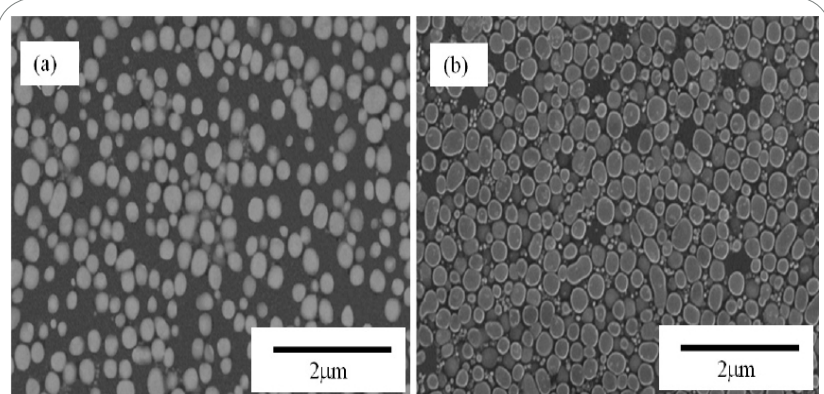

Figure 5: SEM micrographs of specimens aged at $1,050^{\circ} \mathrm{C}$ (a) Alloy B, and (b) Alloy C.

these phases, only the $\gamma^{\prime}$ can provide strengthening, the other phases tend to form coarse platelets. So traditional Ni-Fe base superalloys rely on $\mathrm{Ti}$ addition for metastable $\mathrm{Ni}_{3} \mathrm{Ti} \gamma^{\prime}$ strengthening, however long exposure at temperatures above $650^{\circ} \mathrm{C}$ can cause $\gamma^{\prime}$ to transform to $\eta$, and result loss in strength. An alternative to $\mathrm{Ti}$ is $\mathrm{Nb}$ addition, in the presence of high $\mathrm{Nb} /(\mathrm{Ti}+\mathrm{Al})$ ratios, a metastable phase $\mathrm{Ni}_{3} \mathrm{Nb} \gamma^{n}$ can form for effective strengthening, however, after prolong exposures at temperatures beyond $650^{\circ} \mathrm{C}, \gamma^{\prime \prime}$ can be replaced by $\mathrm{Ni}_{3} \mathrm{Nb} \delta$, which is also a coarse platelets. By contrast, HESAs contain moderate $\mathrm{Fe}$ content and is able to accommodate sufficient $\mathrm{Al}$ content to possess stable phase. Although $\mathrm{Fe}$ is known to degrade the phase stability in conventional $\mathrm{Ni}$ and $\mathrm{Ni}-\mathrm{Fe}$ based superalloys [14], high content of Co in HESA appears to stabilize the microstructure for further 
Citation: Yeh AC, Tsao TK, Chang YJ, Chang KC, Yeh JW, et al. (2015) Developing New Type of High Temperature Alloys-High Entropy Superalloys. Int J Metall Mater Eng 1: 107. doi: http://dx.doi.org/10.15344/2455-2372/2015/107

Page 3 of 4

$\mathrm{Al}, \mathrm{Cr}, \mathrm{Ti}$ additions without jeopardizing phase stability at high temperature. Although Thermo-Calc predicts the formation of BCC and $\mu$ phases in Alloy $\mathrm{C}$ at lower temperatures, however, isothermal ageing at $700^{\circ} \mathrm{C}$ or below conducted so far has not yielded any phase instability, possibly due to very sluggish phase transformation rate in the high entropy alloy system. Hence $\gamma^{\prime}$ precipitates can remain stable in HESA for high temperature strengthening purpose.

In Table 2, compositions of individual $\gamma, \gamma^{\prime}$ phase of Alloy B measured by strain ageing are listed in comparison with a $1^{\text {st }}$ and a $4^{\text {th }}$ generation superalloy [17-19]. HESA $\gamma$ and $\gamma^{\prime}$ possess higher degree of randomness in their ordered structures than those of CM247LC and RR2101. Interestingly, from CM247LC to RR2101, the value of entropy in $\gamma^{\prime}$ phase has not evolved much, and this is due to the later generations of alloys have relied on $\gamma$ forming elements to provide strengthening, hence the entropy of $\gamma$ phase is higher. The potential high temperature strength of HESA can be attributed by high volume fraction of $\gamma^{\prime}$ precipitates, high degree of solid solution strengthening due to lattice distortion, and the increase in APB energy. According to JMatPro calculation (Ni alloys database), the APB energy of $\gamma^{\prime}$ in Alloy B can reach to $0.25 \mathrm{~J} / \mathrm{m}^{2}$, while that of CM247LC is about 0.19 $\mathrm{J} / \mathrm{m} 2$, resulting higher energy penalty for dislocation pairs to cut through HESA $\gamma^{\prime}$

\begin{tabular}{|l|l|l|l|l|}
\hline & Cr activity & $\mathrm{Al}$ activity & Cr activity & $\mathrm{Al}$ activity \\
\hline & $900^{\circ} \mathrm{C}$ & $900{ }^{\circ} \mathrm{C}$ & $1,100{ }^{\circ} \mathrm{C}$ & $1,100{ }^{\circ} \mathrm{C}$ \\
\hline Alloy B & 0.00466 & $5.1165 \times 10^{-8}$ & 0.00213 & $2.38801 \times 10^{-7}$ \\
\hline Alloy C & 0.00308 & $3.62780 \times 10^{-8}$ & 0.00148 & $2.26364 \times 10^{-7}$ \\
\hline CM247LC & 0.00322 & $1.421678 \times 10^{-8}$ & 0.00159 & $1.15643 \times 10^{-7}$ \\
\hline
\end{tabular}

Table 3: $\mathrm{Cr}$ activity and $\mathrm{Al}$ activity calculated by Thermo-Calc (TCNI5 database).

result excellent creep resistances [30]. Furthermore, denser interfacial dislocation network in high misfit alloys can attribute to smaller minimum creep strain rate, since dense dislocation network can hinder pairs of dislocations in $\gamma$ channel from cutting through the $\gamma^{\prime} / \gamma$ interfaces [31]. Future direction to design HESA should be to enlarge its lattice misfit toward negative, and this can be achieved by addition of various $\gamma$ and $\gamma^{\prime}$ forming elements, not restricted to $\mathrm{Al}, \mathrm{Co}, \mathrm{Cr}, \mathrm{Fe}$, $\mathrm{Ni}$, and $\mathrm{Ti}$.

Comparing to traditional superalloys, HESA contains little or no refractory content, the cost of raw materials is cheaper, HESA has lower density, excellent phase stability, and potentials of high temperature strength, and oxidation resistances.

\begin{tabular}{|l|l|l|l|l|l|l|l|l|l|l|l|l|}
\hline at\% & & $\mathrm{Ni}$ & $\mathrm{Al}$ & $\mathrm{Co}$ & $\mathrm{Cr}$ & $\mathrm{Fe}$ & $\mathrm{Ti}$ & $\mathrm{Ta}$ & $\mathrm{W}$ & $\mathrm{Re}$ & $\mathrm{Ru}$ & $\Delta \mathrm{S}_{\text {mix }}$ \\
\hline CM247LC & $\gamma$ & 64.9 & 8.7 & 11.0 & 10.5 & - & 0.7 & 0.9 & 3.1 & - & - \\
\hline & $\gamma^{\prime}$ & 69.4 & 15.5 & 5.8 & 3.4 & - & 1.4 & 2.3 & 2.1 & - \\
\hline RR2101 & $\gamma$ & 46.0 & 3.1 & 26.7 & 9.5 & - & - & 0.3 & 3.6 & 7.9 & 2.9 & $-1.48 \mathrm{R}$ \\
\hline & $\gamma^{\prime}$ & 66.1 & 16.6 & 8.8 & 1.4 & - & - & 2.7 & 3.0 & 0.5 & 0.9 & $-1.12 \mathrm{R}$ \\
\hline Alloy B & $\gamma$ & 32.3 & 4.82 & 24.7 & 18.2 & 16.1 & 3.88 & - & - & - \\
\hline & $\gamma^{\prime}$ & 54.4 & 9.87 & 13.7 & 4.3 & 5.73 & 12.0 & - & $-1.59 \mathrm{R}$ \\
\hline
\end{tabular}

Table 2: Compositions of individual $\gamma, \gamma^{\prime}$ phase, and their $\Delta \mathbf{S}_{\text {mix }}$

By calculating the $\mathrm{Cr}$ activity and $\mathrm{Al}$ activity of HESA (Thermo-Calc TCNI5 database), and make comparisons with those of CM247LC [19], which is known to possess excellent oxidation resistance at high temperatures, we can have some ideas about the potential oxidation resistance of HESA. Values are listed in Table 3, since CM247LC can form continuous protective oxide [19], higher $\mathrm{Cr}$ and $\mathrm{Al}$ activities in HESAs imply that continuous $\mathrm{Cr}_{2} \mathrm{O}_{3}$ and $\mathrm{Al}_{2} \mathrm{O}_{3}$, respectively, can form very rapidly when exposing the alloy to oxidizing environment at high temperatures. After isothermal oxidation at $1,100^{\circ} \mathrm{C}$ for $5 \mathrm{hrs}$, Alloy C can actually form continuous $\mathrm{Al}_{2} \mathrm{O}_{3}$, this is an indication that Alloy $\mathrm{C}$ can have good oxidation resistance at high temperature, Figure 6.

To further advance HESA, future alloy designs can be conducted to control the coarsening kinetics of $\gamma^{\prime}$ phase. Since both Alloy B and C possess spherical $\gamma^{\prime}$ after ageing, Figure 5 , it is an indication that the lattice misfit between $\gamma$ and $\gamma^{\prime}$ is positive. For advanced superalloys, negative lattice misfit between $\gamma$ and $\gamma^{\prime}$ is desired, because the directional coarsening of the $\gamma^{\prime}$ precipitates known as "rafting" is an important microstructural evolution during high temperature creep [20-24]. Rafting is strongly dependent on the sign of applied loading, lattice misfit and elastic constants of $\gamma$ and $\gamma^{\prime}$ phase [25-29]. Lattice misfit $(\delta)$ is defined by the following equation, where a $\gamma^{\prime}$ is the lattice parameter of $\gamma^{\prime}$ and a $\gamma$ is the lattice parameter of $\gamma$ phase:

$$
\delta=2\left(a_{\gamma^{\prime}}-a_{\gamma}\right) /\left(a_{\gamma^{\prime}}-a_{\gamma}\right)
$$

With negative sign of $\delta, \gamma^{\prime}$ can raft in direction perpendicular to the stress axis, effectively hinder the climbing of dislocations and

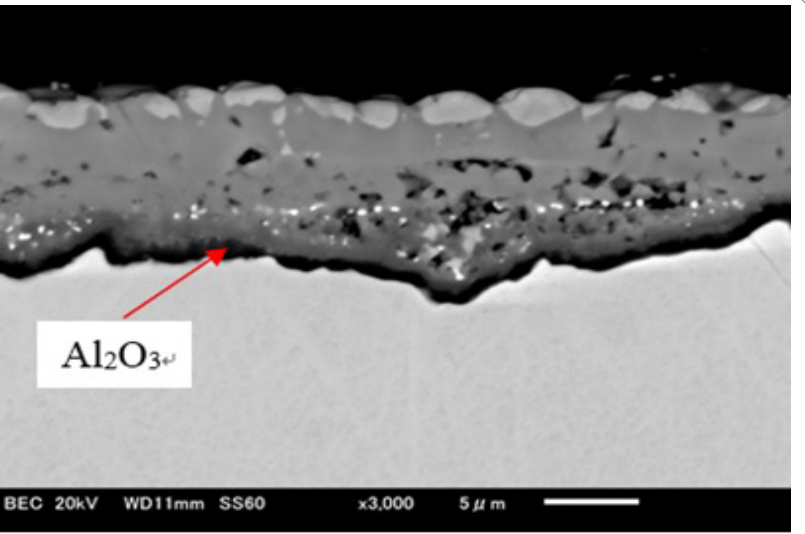

Figure 6: Oxide structure of Alloy $\mathrm{C}$ after $1,100^{\circ} \mathrm{C} / 5 \mathrm{hrs}$.

\section{Conclusion}

- HESA possess high $\gamma^{\prime}$ solvus temperatures and can possess stable $\gamma-\gamma^{\prime}$ microstructures with no $\mu, \sigma, \eta, \delta, \beta$ detrimental phase formations.

- $\quad$ HESA have potential to exhibit good oxidation resistance.

- HESA has density below $8.0 \mathrm{~g} / \mathrm{cm}^{3}$.

- The cost of raw materials for HESA are lower due to little or no refractory content, hence the cost-performances of HESA can surpass that of some superalloys. 
Citation: Yeh AC, Tsao TK, Chang YJ, Chang KC, Yeh JW, et al. (2015) Developing New Type of High Temperature Alloys-High Entropy Superalloys. Int J Metall Mater Eng 1: 107. doi: http://dx.doi.org/10.15344/2455-2372/2015/107

Page 4 of 4

\section{Competing Interests}

The authors declare that they have no competing interests.

\section{Author Contributions}

All the authors substantially contributed to the study conception and design as well as the acquisition and interpretation of the data and drafting the manuscript.

\section{Funding}

Authors would like to thank the financial support from Ministry of Science and Technology, Taiwan (R.O.C.), project grant number: 1032221-E-214 -035, 103-2218-E-007 -019.

\section{References}

1. Sims CT, Stoloff NS, Hagel WC (1987) Superalloys II, Wiley, New Yrok.

2. Reed RC (2006) The superalloys: fundamentals and applications, Cambridge University Press.

3. Reed RC, Tao T, Warnken N (2009) Alloys-By-Design: Application to nickelbased single crystal superalloys. Acta Materialia 57: 5898-5913.

4. Walston WS, Cetel A, MacKay R, O'Hara KS, Duhl D (2004) Join Development of a Fourth Generation Single Crystal Superalloy. Superalloys (TMS,2004), 15-24

5. Zhang JX, Murakumo T, Koizumi Y, Kobayashi T, Harada H (2002) Interfacial dislocation networks strengthening a fourth-generation singlecrystal TMS138 superalloy. Metallurgical and Materials Transactions A 33 3741-3746.

6. Frasier DJ, Whetstone JR, Harris K, Erickson GL, Schwer RE (1990) Process and alloy optimaization for CMSX-4 supper ally single crystal, in cost 501/505 Conference High Temperature Materials for Power Engineering1990, (eds) Bachelet et al., Pub. Kluwer, Dordrecht(Netherlands), 1281-1300.

7. Reed RC, Yeh AC, Tin S, Babu SS, Miller MK (2004) Identification of the partitioning characteristics of ruthenium in single crystal superalloys using atom probe tomography. Scripta Materialia 51: 327-331.

8. Yeh AC, Tin S (2005) Effects of Ru and Re additions on the high temperature flow stresses of Ni-base single crystal superalloys. Scripta Materialia 52: 519-524

9. Yeh AC, Tin $S$ (2006) Effects of $\mathrm{Ru}$ on the high-temperature phase stability of Ni-base single-crystal superalloys. Metallurgical and Materials Transactions A 37: 2621-2631.

10. Yeh AC, Sato A, Kobayashi T, Harada H (2008) On the creep and phase stability of advanced Ni-base single crystal superalloys. Materials Science and Engineering: A 490: 445-451.

11. Kawagishi K, Sato A, Harada H, Yeh AC, Koizumi Y, et al. (2009) Oxidation resistant $\mathrm{Ru}$ containing $\mathrm{Ni}$ base single crystal superalloys. Materials Science and Technology. 25: 271-275.

12. Kawagishi K, Yeh AC, Yokokawa T, Kobayashi T, Koizumi Y, et al. (2012) "Development of oxidation-resistant high-strength superalloy; towards 6th generation single crystal superalloys tms-238" Superalloys 2012: The 12th International Symposium on Superalloy Proceedings of Superalloys 2012: 189-195.

13. Hobbs RA, Tin S, Rae CMF (2005) A castability model based on elemental solid-liquid partitioning in advanced nickel-base single-crystal superalloys. Metallurgical and Materials Transactions A 36: 2761-2773.

14. Yeh JW, Chen SK, Lin SJ, Gan JY, Chin TS, et al. (2004) Nanostructured High-Entropy Alloys with Multiple Principal Elements: Novel Alloy Design Concepts and Outcomes. Advanced Engineering Materials 6: 299-303.

15. Yeh JW (2006) Recent progress in high-entropy alloys. Annales De ChimieScience Des Materiaux 31: 633-648.

16. Yeh AC, Chang YJ, Tsai CW, Wang YC, Yeh JW, et al. (2014) On the Solidification and Phase Stability of a Co-Cr-Fe-Ni-Ti High-Entropy Alloy. Metallurgical and Materials Transactions A 45: 184-190.

17. Reed RC, Yeh AC, Tin S, Babu SS, Miller MK (2004) Identification of the partitioning characteristics of ruthenium in single crystal superalloys using atom probe tomography. Scripta Materialia 51: 327-331.
18. A.C. Yeh, C.M.F. Rae, S. Tin, "High temperature creep of Ru-bearing Ni-base single crystal superalloys", the Tenth International Symposium on Superalloys (Superalloys 2004), 19-23 September 2004, Champion, Pennsylvania, USA, p677-685.

19. Yeh AC, Yang KC, Yeh JW, Kuo CM (2014) Developing an advanced Sibearing DS Ni-base superalloy. Journal of Alloys and Compounds 585: 614-621.

20. Webster GA, Sullivan CP (1967) Some effect of temperature cycle on the creep behavior of a Nickel-Base alloy. Journal of the Institute of Metals 95 : 138-142.

21. Tien JK, Gamble RP (1972) Effects of stress coarsening on coherent particle strengthening. Metallurgical Transactions 3: 2157-2162.

22. Mackay RA, Ebert LJ (1983) The development of directional coarsening of the $\mathrm{Y}^{\prime}$ precipitate in superalloy single crystals. Scripta Metallurgica 17: 1217-1222.

23. Ichitsubo T, Koumoto D, Hirao M, Tanaka K, Osawa M, et al. (2003) Rafting mechanism for Ni-base superalloy under external stress: elastic or elasticplastic phenomena?. Acta Materialia 51: 4033-4044.

24. Serin K, Gobenli G, Eggeler G (2004) On the influence of stress state stress level and temperature on $\gamma$-channel widening in the single crysta superalloy CMSX-4. Materials Science and Engineering a-Structural Materials Properties Microstructure and Processing 387: 133-137.

25. Nabarro FRN, Cress CM, Kotschy P (1996) The thermodynamic driving force for rafting in superalloys. Acta Materialia 44: 3189-3198.

26. Nabarro FRN (1996) Rafting in superalloys. Metallurgical and Materials Transactions. A, Physical Metallurgy and Materials Science 27: 513-530.

27. Laberge CA, Fratzl P, Lebowitz JL (1997) Microscopic model for directional coarsening of precipitates in alloys under external load, Acta Materialia 45: 3949-3962.

28. Svoboda J, Lukas P (1996) Modelling of kinetics of directional coarsening in Ni-superalloys. Acta Materialia 44: 2557-2565.

29. Tien JK, Copley SM (1971) The effect of orientation and sense of applied uniaxial stress on the morphology of coherent gamma prime precipitates in stress annealed nickel-base superalloy crystals. Metallurgical Transactions 2: $543-553$.

30. Zhang JX, Wang JC, Harada H, Koizumi Y (2005) The effect of lattice misfit on the dislocation motion in superalloys during high-temperature low-stress creep. Acta Materialia 53: 4623-4633.

31. Zhang JX, Murakumo T, Harada H, Koizumi Y (2003) Dependence of creep strength on the interfacial dislocations in a fourth generation SC superalloy TMS-138. Scripta Materialia 48: 287-293. 